\title{
Methylene Blue removal from aqueous solutions by activated carbon prepared from $N$. microphyllum (AC-NM): RSM analysis, isotherms and kinetic studies
}

\author{
Mousavi S.A. ${ }^{1}$, Mehralian M. ${ }^{2}$, Khashij M. ${ }^{3,4, *}$ and Parvaneh S. ${ }^{1}$ \\ ${ }^{1}$ Department of Environmental Health Engineering, and Research Center for Environmental Determinants of Health (RCEDH), Faculty of \\ Health, Kermanshah University of Medical Science, Kermanshah, Iran. \\ ${ }^{2}$ Environmental Health Engineering, Kermanshah University of Medical Sciences, Kermanshah, Iran.
}

3Environmental Health Engineering, Shahid Beheshti University of Medical Sciences, Tehran, Iran. ${ }^{4}$ Environmental Sciences and Technology Research center, Department of Environmental Health Engineering; Shahid Sadoughi University of Medical Sciences, Yazd, Iran

Received: 14/07/2017, Accepted: 30/11/2017, Available online: 20/12/2017

*to whom all correspondence should be addressed: e-mail: m.khashij@yahoo.com

\begin{abstract}
This study was conducted to remove Methylene Blue (MB) from aqueous solution using activated carbon prepared from N. microphyllum (AC-NM) as a new, cheap, and nontoxic. Design of experiments based on Response Surface Methodology (RSM) conducted to investigate the effect of variables namely; initial dye concentration, $\mathrm{pH}$, contact time and absorbent dosage. An empirical model was developed applying ANOVA analysis. The interaction effects of all factors and their optimization have been carried out using RSM. Dye removal efficiency increased to more than $90 \%$ with increasing $\mathrm{pH}$ and initial concentration of dye from 3 to 11 and 10 to $210 \mathrm{mg} / \mathrm{L}$, respectively under 1.1 to $1.4 \mathrm{~g} / \mathrm{L}$ of absorbent dosage. Among factors, initial concentration of $\mathrm{MB}$ known as an important factor with $\mathrm{P}$ value $<0.0001$. The experimental data are fitted with Freundlich model based on multilayer adsorption states $\left(R^{2}=0.99\right)$. The adsorption kinetics well described by second order model with $R^{2}=0.98$. This novel absorbent has different advantages such as low cost, high ability to absorb pollutants and easily available that can be suggested for water and wastewater treatment.
\end{abstract}

Keywords: Absorption, Activated Carbon, Decolorization, Methylene Blue, N. microphyllum

\section{Introduction}

Nowadays, one of the major challenges for environment and human life due to their adverse effects is synthetic dyes (Hayat et al., 2015; Tan et al., 2015). Synthetic dyes are intensely compounds having general applications in different industries such as chemical and dye manufacturing, textile, paper, leather and plastics (Özer and Dursun 2007; Low et al., 2011; Albadarin and Mangwandi 2015; Mitrogiannis et al., 2015) with structural diversity including: acidic, basic, reactive, azo, anthraquinone-based, and metal complex dyes (Rohilla, 2012). Those aforementioned dyes have different effects on environment; for example, they can be cause of reduction of sunlight penetration, oxygen transfer limitation, and also are stable chemical and toxic for fauna and flora, when release into environment. Furthermore, they cause irreversible damages on human health such as mutagenic, teratogenic and carcinogenic effects (Bouaziz et al., 2015; Dotto et al., 2015; Yuan et al., 2016).

Amongst these dyes, the Methylene Blue (MB) is widely used for dying wood, cotton and silk (Hameed et al., 2007; Li et al., 2013) which can be cause of methemoglobinemia, nausea, vomiting and mental confusion(Mitrogiannis et al., 2015). For this reason, removal of it from effluent containing dye is necessary. However, there are chemical and biological methods (like coagulation/flocculation, advanced oxidation processes, membrane filtration and ozonation) for treatment of dye effluents but these effluents are hardly treated by conventional biological wastewater treatments (Zhang et al., 2010; Li et al., 2013). At the present time, adsorption is reliable to be a simple technique and successful in water and wastewater treatment process and the success of the method largely depends on the evolution of a capable adsorbent (Khashij et al., 2016). Variety of absorbents has been studied to removal of $\mathrm{MB}$ from water and wastewater such as Clay, Clinoptilolite, Almond Gum, Rice Husk, Fly Ash and etc (Fernandes et al., 2007; Hameed et al., 2007; Özer and Dursun 2007; Almeida et al., 2009; Ghaedi et al., 2012; Liu et al., 2012; Li et al., 2013; Bouaziz et al., 2015). Recently, agricultural waste as low cost adsorbent, availability and non-toxicity is noteworthy. In the meantime, $N$. microphyllum is widespread as an aquatic plant species and activated carbon prepared (PAC) from it can be considered in removal of Methylene Blue and other pollutants (Almasi et al., 2017).

The removal efficiencies of dye in adsorption systems are often influenced by many parameters such as dosage of adsorbent, concentration of absorbate, contact time, and 
$\mathrm{pH}$ (Cui et al., 2016). Therefore, using of the method for optimization of parameters is necessary. Recently, one of the methods for optimization is RSM technique (Liu et al., 2012). RSM is a collection of mathematical and statistical technique that involves experiments based on the multivariate non-linear model and it can be used for studying the effect of several factors (Mousavi et al. 2014; Mousavi and Ibrahim, 2014). In this model, all parameters are varied overset of experimental runs; RSM can make simple and efficient modeling utilization (Bezerra et al., 2008). N. microphyllum had perennial growing as well as there is no information in the literature regard to the use of N.microphyllum originating from this type of geographical location, a fact which confirms without doubt the novelty of this work. So, the objective of this study was to determine the effectiveness of AC-NM as a novel adsorbent in removing $\mathrm{MB}$ dye and optimization of independent factors with RSM.

\section{Experimental}

\subsection{Material and Reagents}

For experiments, Methylene Blue $\left(\mathrm{C}_{16} \mathrm{H}_{18} \mathrm{~N}_{3} \mathrm{SCl}\right)$ with $98 \%$ purity - (Merck) was used for preparing the stock solution. All the reagents were prepared with deionized water. All runs have been conducted by using solution from stock solution at the desired concentration.

\subsection{Preparation of Absorbent}

The AC-NM that was obtained from Gilangharb (city of Kermanshah in Iran). Initially, N. microphyllum plant was washed with distilled water and cut to desired size of $5 \mathrm{~cm}$. Then, raw materials were dried at $150{ }^{\circ} \mathrm{C}$ for 2 hours using an oven model Memert 854- Germany. Samples were sieved to obtain mesh of $50(0.2 \mathrm{~mm})$. After that sieved plants carbonized in oven at $500{ }^{\circ} \mathrm{C}$ for 4 hours. Activation was conducted in a furnace under purified nitrogen

Table 1. Isotherms and Kinetic models of adsorption
(99.99\%) flow of $150 \mathrm{ml} / \mathrm{min}$ to make an inert atmosphere. Finally, absorbent was dried at ambient temperature and stored in a capped bottle.

\subsection{Adsorbent Characterization}

AC-NM was characterized using SEM analyses. SEM images of all samples were taken to determined surface textures of PAC, using scanning electron microscope (XI-30 ESEMFEG Company, USA). The FTIR spectra of the AC were analyzed between 4000 and $600 \mathrm{~cm}^{-1}$ in a Perkin-Elmer 1720 spectrometer and samples were prepared by mixing carbon powder and $\mathrm{KBr}$ at the weight ratio of 1:400. Also, the specific surface area and total pore volume $\left(V_{t o t}\right)$ were determined by $\mathrm{N}_{2}$ adsorption isotherms (BET) via the nitrogen uptake at relative pressure of 0.88 and ambient temperature of $298 \mathrm{~K}$ by SA-9600 analyzer (HORIBA, Germany).

\subsection{Batch Adsorption Studies}

The experiments were carried out in a glass beaker with total volume of $250 \mathrm{~mL}$. The reactor consisted of a $7 \mathrm{~cm}$ diameter by $9 \mathrm{~cm}$ height. Homogeneity achieved by applying magnetic shaker (JENWAY SELECTA 1000, UK) at $150 \mathrm{rpm}$ for all tests, when temperature was $25 \pm 2^{\circ} \mathrm{C}$. Batch experiments were done with four factors namely initial $\mathrm{pH}$ (3-11), Dosage of adsorbent (0.2-1.4 g/L), initial concentration (10-210 mg/L) and contact time (10-50 $\mathrm{min}$ ). Subsequently, samples were centrifuged at $3800 \mathrm{rpm}$ for 5 minutes.

\subsection{Isotherm, Kinetic and Experimental Modeling}

Interaction between MB with adsorbent toward surface properties is described with different isotherm and kinetic models. Isotherm models and parameters are illustrated in Table 1 . In addition, the design of experiments (DOE) in order to eliminate errors systematically was conducted.

\begin{tabular}{|c|c|c|c|}
\hline Isotherms & Equation & kinetics & Equation \\
\hline Freundlich & $\log q_{e}=\log k_{f}+\frac{1}{n} \log c_{e}$ & First-Order & $\frac{d q_{t}}{d t}=k_{1}\left(q_{e}-q_{t}\right)$ \\
\hline Langmuir & $\frac{\mathrm{C}_{\mathrm{e}}}{\mathrm{q}_{\mathrm{e}}}=\frac{1}{\mathrm{bQ}_{\max }}+\frac{\mathrm{c}_{\mathrm{e}}}{\mathrm{Q}_{\max }}$ & Second-Order & $\frac{d q_{t}}{d t}=k_{2}\left(q_{e}-q_{t}\right)^{2}$ \\
\hline Temkin & $\mathrm{q}_{\mathrm{e}}=\frac{\mathrm{RT}}{\mathrm{b}} \ln \mathrm{K}_{\mathrm{t}} \mathrm{C}_{\mathrm{e}}$ & $\begin{array}{l}\text { Intraparticle } \\
\text { diffusion }\end{array}$ & $q_{t}=k t^{1 / 2}$ \\
\hline Redlich-Peterson & $\mathrm{q}_{\mathrm{e}}=\frac{\mathrm{K}_{\mathrm{RP}} \mathrm{C}_{\mathrm{e}}}{1+\alpha \mathrm{C}_{\mathrm{e}}^{\beta}}$ & Elovich & $q_{t}=1 / b \ln a b+1 / b \ln t$ \\
\hline Parameter & Description & Parameter & Description \\
\hline$q_{e}$ & Adsorption equilibrium rate $(\mathrm{mg} / \mathrm{g})$ & a & Initial adsorption rate $(\mathrm{mg} /(\mathrm{g} \mathrm{min})$ \\
\hline$q_{\max }$ & Dye adsorbed (mg/g) & $1 / b$ & Number of sites available $(\mathrm{mg} / \mathrm{g})$ \\
\hline $\mathrm{K}_{\mathrm{F}}$ & Constant $(\mathrm{mg} / \mathrm{g})(\mathrm{L} / \mathrm{g})^{-1 / \mathrm{n}}$ & $\mathrm{K}_{\mathrm{t}}$ & Temkin equilibrium constant \\
\hline b & Langmuir constant (L/mg) & b & Energy of adsorption(j) \\
\hline $\mathrm{n}$ & Freundlich constants & $\mathrm{T}$ & Absolute temperature in $\mathrm{K}\left({ }^{\circ} \mathrm{C}\right)$ \\
\hline $\mathrm{C}_{\mathrm{e}}$ & Final concentration $(\mathrm{mg} / \mathrm{g})$ & $\mathrm{R}$ & Ideal gas constant $\left(8.314 \mathrm{~J} \mathrm{~mol}^{-1} \mathrm{~K}^{-1}\right)$ \\
\hline k & Intraparticle diffusion constant & $\alpha$ & Redlich-Peterson constant \\
\hline $\mathrm{C}$ & Boundary layer thickness (mg/g) & $\beta$ & Redlich-Peterson constant \\
\hline
\end{tabular}


This technique has the ability to optimization of the experiments and designed to test an empirical model. The most common way for optimization of multivariables is optimizing the individual variable while the other variables are constant. Because cases like time-consuming and disregarding the reaction between variables, this method not been paid to optimal results. For this reason, a statistical method for determine the effects between dependent and independent variables is designed. Among such methods, the response surface methodology (RSM) is a statistical technique for modeling of experiments. Modeling by this method is able to determine the effective independent variables namely concentration (factor $A$ ), adsorbent dosage (factor $\mathrm{B}$ ), $\mathrm{pH}$ (factor $\mathrm{C}$ ), contact time (factor D), and their interactive influences on $M B$ adsorption at a limited number of designed runs, that is by using the central composite design (CCD) via Design-Expert (ver, 8.0) software relationships between the variables will be provided. The reasonable range of $\mathrm{MB}$ dye (actual value = 10, 50 and $200 \mathrm{mg} / \mathrm{L}$ ) and adsorbent dosage (AC-NM; actual value $=0.2,1$ and $1.4 \mathrm{~g} / \mathrm{L}$ ) were selected according to the previous studies that the coded value term was used to represent the independent variables at two levels, which consist of -1 (low level), and +1 (high level).

Table 2. Level of various independent variables at coded values of CCD

\begin{tabular}{cccc}
\hline \multirow{2}{*}{ Symbol } & \multirow{2}{*}{ Independent variables } & \multicolumn{2}{c}{ Coded levels } \\
\cline { 3 - 4 } & & High & Low \\
\hline $\mathrm{A}$ & Concentration, $\mathrm{mg} / \mathrm{L}$ & 200 & 10 \\
\hline $\mathrm{B}$ & Dosage, $\mathrm{g}$ & 1.4 & 0.2 \\
\hline $\mathrm{C}$ & $\mathrm{pH}$ & 11 & 3 \\
\hline $\mathrm{D}$ & Contact Time, min & 50 & 10
\end{tabular}

As shown in Table 2, the experimental conditions for adsorption process based on CCD with a factorial matrix of 78 steady state runs were designed. After accomplishing the experiments at a set value of independent variables (concentration, dosage of adsorbent, contact time and $\mathrm{pH}$ ), the experimental data according to Table 1 were used to develop empirical models based on actual factors (AF) and

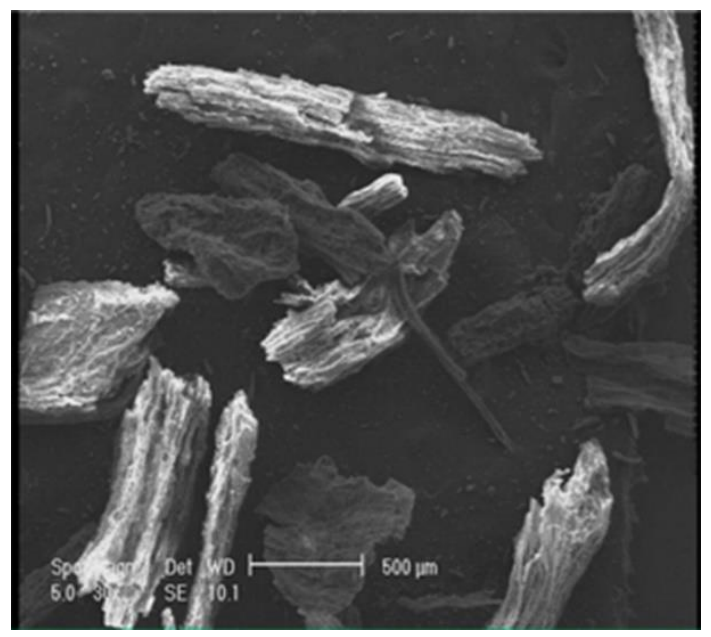

coded factors (CF), using analysis of variance (ANOVA). The significance of the variables was recognized based on the confidence levels above 95\% ( $P<0.05)$ in the polynomial model. The quadratic model based on Eq. (1) was used to estimate the coefficients of the statistical model:

$$
Y=\beta_{0}+\sum_{i=1}^{k} \beta_{i} x_{i}+\sum_{i=1}^{k} \beta_{i j} x_{i i}^{2}+\sum_{i<j}^{k} \sum \beta_{i j} x_{i} x_{j}+e
$$

Where $i$ represents linear coefficient, $j$ stands for the quadratic coefficients, $b$ is the regression coefficient, $x$ represents independent variables, $k$ is the number of studied and optimized factors in the experiment and $e$ is the random error.

\subsection{Analysis Procedure}

The concentration of MB is determined by the $2120 \mathrm{C}$ standard methods spectrophotometer method(Federation and Association 2005). The samples measured at $675 \mathrm{~nm}$ in a UV- visible spectrophotometer (Jenway6305-Germany). The results were analyzed using analysis of variance (ANOVA) (Design Expert Software). Decolorization percentage was determined using the (2) formula:

$$
\text { Decolorization }(\%)=\frac{\left(C_{i}-C_{f}\right)}{C_{i}} \times 100 \%
$$

Where, $C_{i}$ is the initial concentration of dye $(\mathrm{mg} / \mathrm{L}), \mathrm{C}_{\mathrm{f}}$ is the final concentration $(\mathrm{mg} / \mathrm{L})$.

\section{Results and discussion}

\subsection{Characterization of carbon}

SEM images of activated carbon are shown in Figure 1. The activated carbon has crevices, cracks and various sizes of crystals in large pores that can be due to activation of adsorbent. This result is also in good accordance with the $B E T$ results, leading to relatively high BET surface area of $1940 \mathrm{~m}^{2} / \mathrm{g}$. FTIR spectroscopy before and after activation is shown in Figure 2.

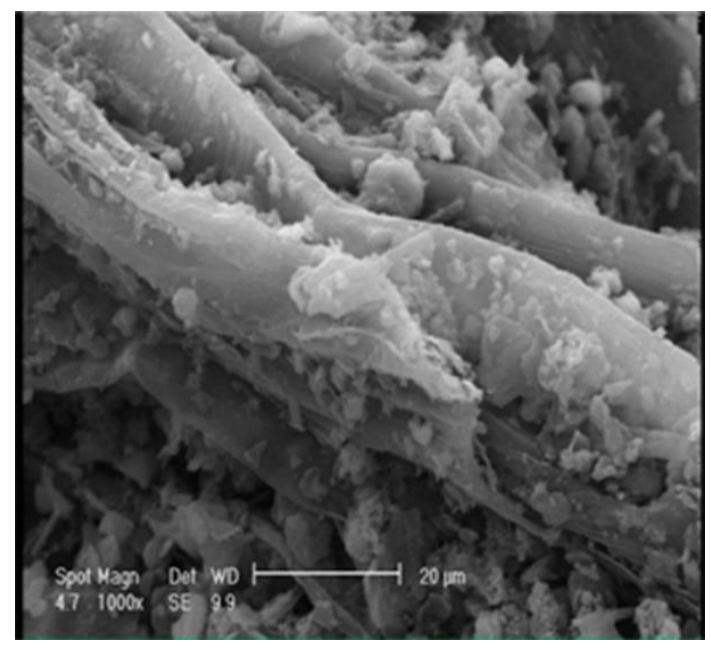

Figure 1. SEM of activated carbon prepared from N. microphyllum (AC-NM) 


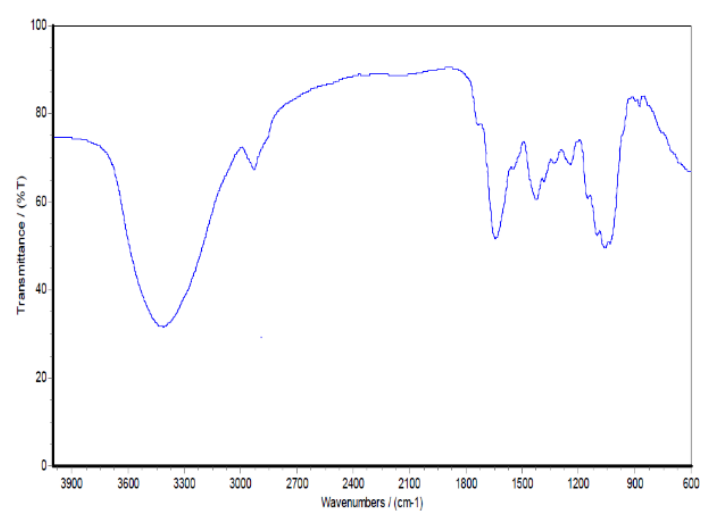

(a)

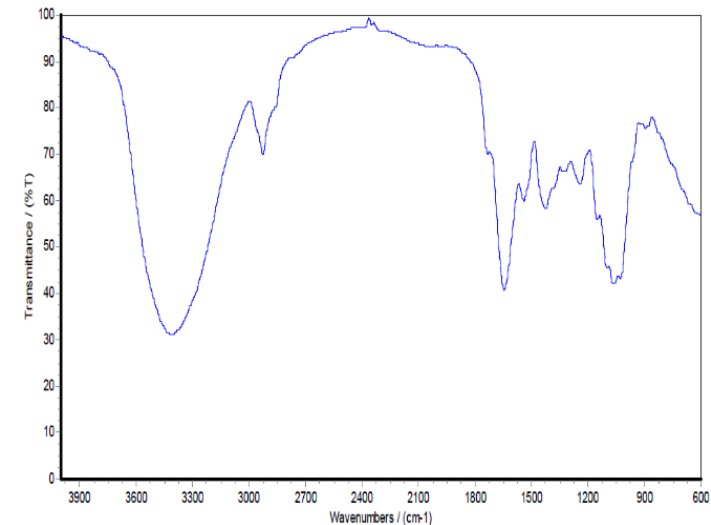

(b)

Figure 2. FTIR spectroscopy before (a) and after (b) activation

Based on FTIR spectra, there are different types of functional groups on adsorbent surface (Vickers et al., 2000). These functional groups are assignments to four main groups (Carboxylic acids, Phenolic groups, Pyridinelike groups and Nitro groups). The band at 3200 to $3600 \mathrm{~cm}^{-1}$ corresponded with $\mathrm{O}-\mathrm{H}$ stretching vibration of hydroxyl functional groups. The peak at 1700 to $1800 \mathrm{~cm}^{-1}$ associated to $\mathrm{C}=\mathrm{O}$ stretching of the carboxyl groups(Jia et al., 2002). The intensity of this peak gradually increases with activation of adsorbent. So that, the peak about $1400 \mathrm{~cm}^{-1}$ and $1500 \mathrm{~cm}^{-1}$ is associated to carboxyl structures (Siriwardane et al., 2005). For example, carboxylic groups such as $\mathrm{C}=\mathrm{O}$ and $\mathrm{C}-\mathrm{O}$ have the peak at
$1400 \mathrm{~cm}^{-1}$ which it can be corresponded to oxygen containing functional groups. Also, there is weak peak attributed $\mathrm{C}-\mathrm{O}$ group in phenol, alcohol, ether at about $1150 \mathrm{~cm}^{-1}$ (Drage et al., 2007). It could also be attributed to carboxylic groups (Carrott et al., 2001), including $-\mathrm{CO}_{3}$ group and the phenolic $-\mathrm{OH}$ group (Plaza et al., 2009). The peak at about $960 \mathrm{~cm}^{-1}$ may be due to $\mathrm{C}-\mathrm{C}$ or $\mathrm{C}-\mathrm{H}$ groups stretching vibration. All the functional groups on activated carbon depending on the solution $\mathrm{pH}$ can have positive or negative charge in the surface (Plaza et al., 2009). In additions, the capacity of PAC towards MB dye was compared with those of other activated carbon from different sources, as summarized in Table 3.

Table 3. Maximum adsorption capacities and surface area of different adsorbents for $M B$

\begin{tabular}{cccc}
\hline Adsorbent & $\begin{array}{c}\text { Maximum adsorption } \\
\text { capacity }(\mathbf{m g} / \mathbf{g})\end{array}$ & Surface area $\left(\mathbf{m}^{2} / \mathbf{g}\right)$ & References \\
\hline Activated carbon prepared from & 143.53 & 318.4 & (Marrakchi et al., 2017) \\
chitosan flakes & 359 & 1135 & (Islam et al., 2017) \\
Activated carbon of rattan hydrochar & 75.37 & 2869 & (Kumar and Jena, 2016) \\
Activated carbon from Fox nutshell & 221 & 514 & (Martins and Nunes, 2015) \\
Commercial activated arbon & 67.5 & 1940 & - \\
This work & & &
\end{tabular}

\subsection{Statistical analysis and development of mathematical model}

Results of ANOVA showed that the regression model for $\mathrm{MB}$ removal is tabulated in Table (4). The factorial designs are used when the curvature in the response surface is concerned. Also, with the number of large factors, the factorial design can be as alternative approach (Wu et al., 2012). The empirical model based on aforementioned parameters is valid (Eq. (3)):

$\% R_{M B}=30.07-30.77(A)+2.17(B)+3.20(C)+0.84(D)+1.67(A B)+2.49(A C)+0.52(A D)-0.24(B C)-0.16(B D)+1.39(C D)+14.20\left(A^{2}\right)+10.41\left(B^{2}\right)+15.15\left(C^{2}\right)-2.99\left(D^{2}\right)$

From Eq. (3), it can be seen that the dose of adsorbent, $\mathrm{pH}$ and contact time have positive effect on the adsorption efficiency and initial concentration has negative effect on the efficiency. The positive value of variables points out an effect that favors the optimization, whereas a negative value presents an inverse relationship between the factors and the responses. The coefficient value $\left(R^{2}\right)$ determines the fitness of the models. The $R^{2}(\mathrm{Adj})$ and $R^{2}$ (pred) should be within approximately 0.2 of each other to be in reasonable agreement. The close correspondence between $R^{2}$ adj and $R^{2}$ indicates unnecessary variables have not been included. Beside P-value is used to determine the effects in the model that are statistically significant. P-value being closer to zero was used to data significance (Srinivasan and Viraraghavan, 2010). when p-value is less than 0.05, the interaction effects of each factors are statistically 
significant (Demim et al., 2014). As can be seen from Table 3 , the p-values of $A$ (concentration) is 0.0001 , which indicates that this variable is significant on the removal of $\mathrm{MB}$ by PAC but the $\mathrm{p}$-values of $\mathrm{B}(\mathrm{PAC}), \mathrm{C}(\mathrm{pH})$ and $\mathrm{D}$ (time) indicates that these variables are not significant in $M B$ removal $(p>0.05)$. Factors considered affect on response differently. So, factor with high value lead to higher mean responses except factor of time for MB removal.
Alternatively, the factors $A$ to have a greater effect on the responses by PAC, with a steeply slope. In other hand, lackof-fit is useful for model adequacy by comparison between pure and residual error which that lacking significance is desirable when F-value is small (Mousavi et al., 2012). As noted in Table 3, lack-of-fit for all factors was not significant ( $p>0.05)$ except $A(p<0.0001)$.

Table 4. Developed models and ANOVA results using Design Expert 8.0.0 for studied responses

\begin{tabular}{|c|c|c|c|c|c|}
\hline Source & Sum of squares & df & Mean square & F value & p-ValueProb $>F$ \\
\hline Model & 25496.2 & 14 & 1821.1 & 36.03 & $<0.0001$ \\
\hline A & 15618.5 & 1 & 15618.5 & 309.01 & $<0.0001$ \\
\hline $\mathrm{B}$ & 77.91 & 1 & 77.91 & 1.54 & 0.23 \\
\hline $\mathrm{C}$ & 169.4 & 1 & 169.4 & 3.35 & 0.08 \\
\hline $\mathrm{D}$ & 11.37 & 1 & 11.37 & 0.28 & 0.63 \\
\hline$A B$ & 44.46 & 1 & 44.46 & 0.88 & 0.36 \\
\hline$A C$ & 99.25 & 1 & 99.25 & 1.96 & 0.18 \\
\hline$A D$ & 4.34 & 1 & 4.34 & 0.086 & 0.77 \\
\hline $\mathrm{BC}$ & 0.96 & 1 & 0.96 & 0.019 & 0.89 \\
\hline $\mathrm{BD}$ & 0.42 & 1 & 0.42 & 0.0082 & 0.92 \\
\hline$C D$ & 31.00 & 1 & 31.00 & 0.61 & 0.44 \\
\hline$A^{2}$ & 33.58 & 1 & 33.58 & 0.66 & 0.42 \\
\hline $\mathrm{B}^{2}$ & 18.04 & 1 & 18.04 & 0.36 & 0.55 \\
\hline$C^{2}$ & 38.21 & 1 & 38.21 & 0.76 & 0.39 \\
\hline$D^{2}$ & 1.48 & 1 & 1.48 & 0.029 & 0.86 \\
\hline Residual & 758.16 & 15 & 758.16 & & \\
\hline Lack of fit & 580.22 & 10 & 580.22 & 1.63 & 0.30 \\
\hline Pure error & 177.94 & 5 & 177.94 & & \\
\hline Cor total & 26254.4 & 29 & & & \\
\hline$R^{2}=0.97$ & $R^{2}(\operatorname{Adj})=0.94$ & & red) $=0.90$ & & \\
\hline
\end{tabular}

\subsection{Effect of $\mathrm{pH}$ and Contact Time}

Adsorption experiments were carried out to investigate the combined effect of initial solution $\mathrm{pH}$ and contact time on the dye removal (Figure 3).

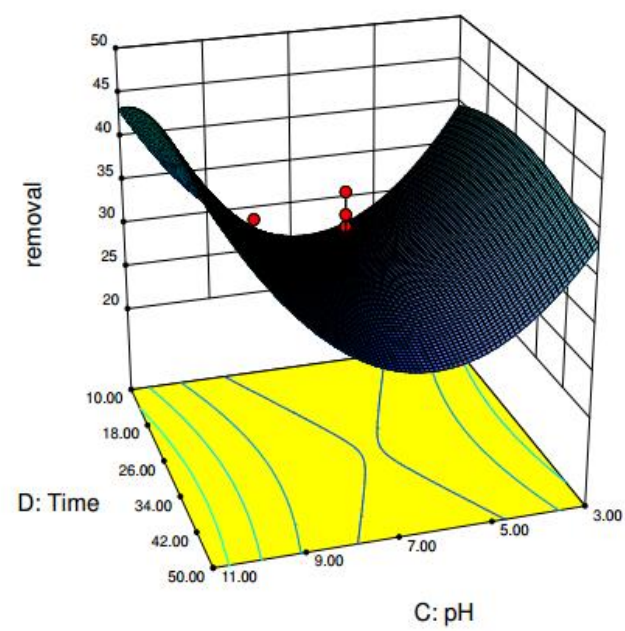

Figure 3. Effect of $\mathrm{pH}$ and contact time on the removal of $\mathrm{MB}$

The $\mathrm{MB}$ removal increases with $\mathrm{pH}$ from 3 to 11 and maximum removal obtained $45 \%$ with $0.8 \mathrm{~g} / \mathrm{L}$ of PAC and
$110 \mathrm{mg} / \mathrm{L}$ of initial dye concentration. It is evident that both variables have a strong influence on the MB removal. Results showed that when $\mathrm{pH}$ was increased from 3 to 11 under constant concentration of $110 \mathrm{mg} / \mathrm{L}$ and $0.8 \mathrm{~g} / \mathrm{L}$ of adsorbent dose, the static repulsion force decreases and the $\mathrm{MB}$ adsorption increases. When $\mathrm{pH}$ value increased from 3 to 11, the surface of PAC was negatively charged which resulted to a higher adsorption capacity (Turan Beyli et al., 2015). Indeed, positive charge and electrostatic force because of protonation phenomena of functional group at low $\mathrm{pH}$ is high and PAC have a high absorption capacity (Ghaedi et al., 2012).

On the other hand, by reducing the electrostatic force between the adsorbate and the electrical double layer surrounding the adsorbent, $\mathrm{MB}$ acts as a proton conjugate. So, when the $\mathrm{pH}$ is greater than $\mathrm{pKa}(\mathrm{pH}>\mathrm{pKa})$, the pollutant converted to anionic state. Considering that $\mathrm{pKa}$ of $\mathrm{MB}$ is 3.8, the removal of it in alkaline $\mathrm{pH}$ is increased. This results due to reduction of repulsive forces between positive groups and negative hydroxyl ions (Veličković et al., 2016).

Also, the sorption capacity of the MB was increased at the high contact time due to the enough time and more availability of binding sites for the sorption. Thus, due to these two factors, raised of $\mathrm{pH}$ and contact time, increased of removal $\mathrm{MB}$ in solution. 


\subsection{Effect of initial concentration and carbon dosage}

The combined effects of PAC dosage (0.2-1.4 g/L) and concentration (10-210 mg/L) on MB removal are shown in Figure 4. It was observed that percentage removal of $\mathrm{MB}$ increased (85\%) with increasing the amount of concentration as well as PAC at a constant time of $30 \mathrm{~min}$ and $\mathrm{pH}=7$. This means that higher values of $\mathrm{MB}$ removal can be obtained by simultaneous increase in PAC and initial concentration of dye. This may be due to the saturation of the adsorption sites at higher $\mathrm{MB}$ concentrations. The MB concentration provides an important driving force to overcome all mass transfer resistance but this issue in contrast of Ghaedia et al., (2012) study because of saturation of PAC surface pores (Hayat et al., 2015).

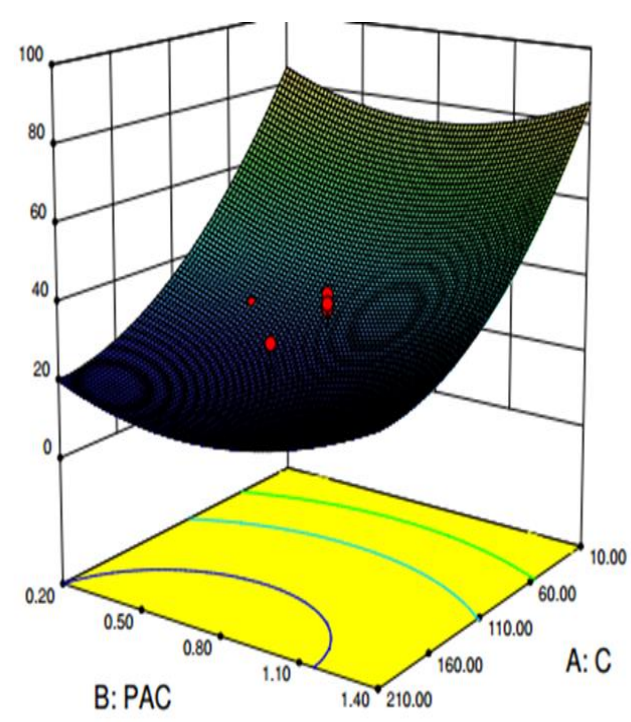

Figure 4. Effect of PAC dosage and dye concentration on the removal of $\mathrm{MB}$

\subsection{Effect of PAC dosage and time}

Figure 5 illustrates the interaction effects of PAC dosage and contact time in the response process. The time showed a little effect, while a remarkable effect of PAC dosage on the removal of MB by PAC is shown in Figure 5.

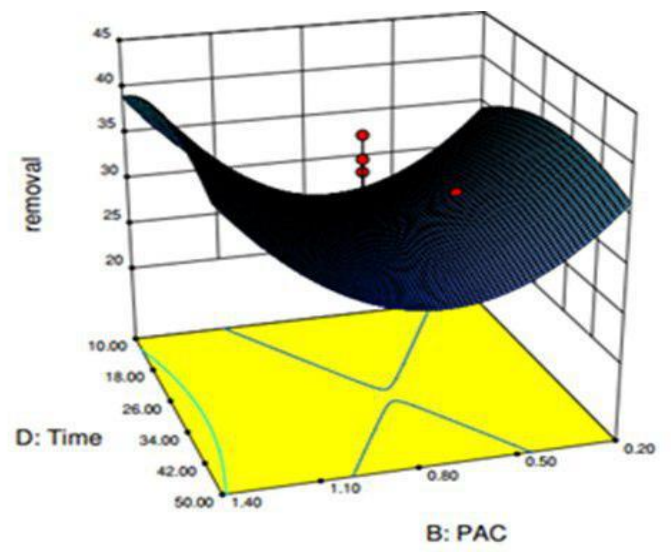

Figure 5. Effect of PAC dosage and contact time on the percentage removal of $\mathrm{MB}$
In addition, the removal of MB decreased with the time increased. That is probably because the saturation of the adsorption sites at higher time (Hayat, Mahmood et al. 2015). As shown in Figure 3, the MB removal increased from $25 \%$ to $38 \%$ at a concentration of $110 \mathrm{mg} / \mathrm{L}$ and contact time of $10-50 \mathrm{~min}$, with an initial solution $\mathrm{pH}=7$.

\subsection{Optimization of experimental conditions}

A multiple method was used for the optimization of any combination of four goals ( $\mathrm{pH}$, contact time, concentration and removal of $\mathrm{MB}$ ). So for achieving the best quality of effluent each input variable and response can be selected through this method. However, PAC dosage, $\mathrm{pH}$ and concentration increasing has ability to higher abortion of MB dye but detection of mentions factors optimized value is useful. Figure 6 shows the overlay plot which highlighted the optimum areas for achieved dye discharged standard. However, there is maximum allowable of color concentration for countries but based on global effluent guideline, offensive color is not accepted for wastewater discharged to surface waters (STRAUSS, 2007). Therefore, by conducting seeking at 3 starting points for $\mathrm{MB}$, the best local maximum response was found to be at initial solution $\mathrm{pH}=3$, concentration $10 \mathrm{mg} / \mathrm{L}$ and contact time of $10 \mathrm{~min}$ with absorbent dosage of $0.2 \mathrm{~g} / \mathrm{L}$. The maximum response ( $\mathrm{MB}$ removal) was $97 \%$. So, this result to make for achieving dye discharge standard under optimum condition is utilizable and verified that the model was able to make an acceptable prediction for the optimum conditions.

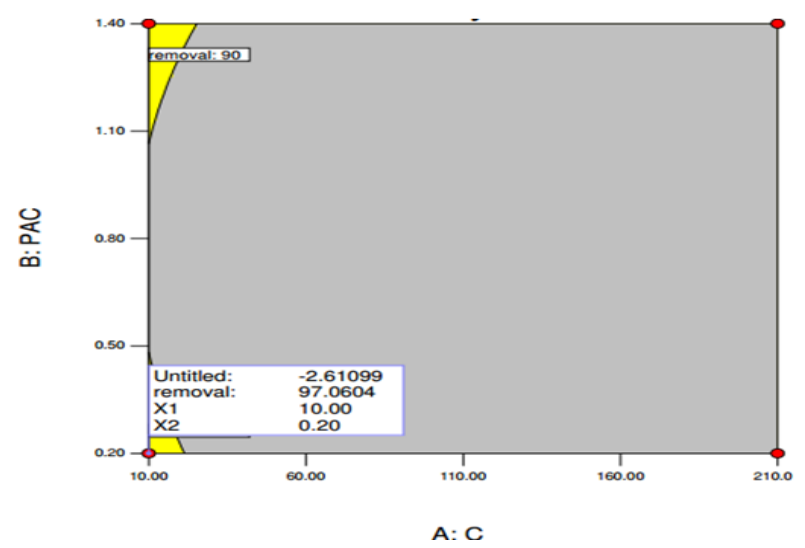

Figure 6. Overlay plot in order to optimization of $\mathrm{MB}$ removal

\subsection{Adsorption isotherms and kinetics}

The results in Table 5 showed Freundlich isotherm states the best interpretation of $\mathrm{MB}$ adsorption with $\mathrm{R}^{2}=0.99$. The high correlation to Freundlich isotherm implies the multilayer adsorption that in direct to Hameed et al., (2007) study (Hameed et al., 2007) but this study does not support the findings of Ghaedia (2012), Rodriguez(2009), Tan (2008) and Ozer (2007) studies (Özer and Dursun, 2007; Tan et al., 2008; Rodríguez et al., 2009; Ghaedi et al., 2012). Whatever Freundlich constants ( $n$ and $k$ ) is greater, demonstrated that uptake of MB by adsorbent increased. Furthermore, the absorption kinetics correspond with the Zhang et al., (2010) study showed Freundlich adsorption 
isotherm due to external surface adsorption as well as intraparticle diffusion (Zhang et al., 2010).

Table 5. Absorption isotherms parameters and kinetics study for MB adsorption by AC-NM

\begin{tabular}{|c|c|c|c|c|c|c|c|c|c|c|c|}
\hline \multicolumn{12}{|c|}{ Isotherms } \\
\hline \multicolumn{3}{|c|}{ Freundlich } & \multicolumn{3}{|c|}{ Langmuir } & \multicolumn{3}{|c|}{ Temkin } & \multicolumn{3}{|c|}{ Redlich-Peterson } \\
\hline $\mathbf{R}^{\mathbf{2}}$ & $\mathbf{n}$ & $\mathbf{k}$ & $\mathbf{R}^{2}$ & b & $\mathbf{q}_{(\max )}$ & $\mathbf{R}^{\mathbf{2}}$ & $b_{t}$ & $\mathbf{K}_{\mathrm{t}}$ & $\mathbf{R}^{2}$ & $\alpha$ & $K_{R T}$ \\
\hline 0.99 & 0.17 & 39.5 & 0.92 & 0.04 & 43.3 & 0.06 & 0.14 & 0.07 & 0.02 & 0.01 & 15.6 \\
\hline \multicolumn{12}{|c|}{ Liner Equation } \\
\hline \multicolumn{3}{|c|}{$Y=5.61 X-13.94$} & \multicolumn{3}{|c|}{$Y=-0.2856 X+7.068$} & \multicolumn{3}{|c|}{$Y=2.103 X+14.09$} & \multicolumn{3}{|c|}{$Y=-0.001 X+0.064$} \\
\hline \multicolumn{12}{|c|}{ Kinetics } \\
\hline \multicolumn{3}{|c|}{ First-Order } & \multicolumn{3}{|c|}{ Second-Order } & \multicolumn{3}{|c|}{ Intraparticle diffusion } & \multicolumn{3}{|c|}{ Elovich } \\
\hline $\mathrm{K}_{2}$ & & $\mathbf{R}^{2}$ & $\mathrm{~K}_{1}$ & & $\mathbf{R}^{2}$ & C & & $\mathbf{R}^{2}$ & a & & $\mathbf{R}^{2}$ \\
\hline 0.001 & & 0.94 & 0.02 & & 0.98 & 0.01 & & 0.23 & 0.007 & & 0.069 \\
\hline \multicolumn{12}{|c|}{ Linear Equation } \\
\hline \multicolumn{3}{|c|}{$Y=-0.0013 X+3.630$} & \multicolumn{3}{|c|}{$Y=0.1151 X+0.7045$} & \multicolumn{3}{|c|}{$Y=2.1033 X+14.095$} & \multicolumn{3}{|c|}{$Y=-4.0105 X+67.5$} \\
\hline
\end{tabular}

Also, to elucidate of adsorption mechanisms was tested kinetics such as pseudo first-order and pseudo secondorder and data shown in Table 5. The adsorption kinetics well described by second order model with $\mathrm{R}^{2}=0.98$ that supported with Ghaedi et al., (2012) for Kinetic and isotherm study for removal of Methylene blue (Ghaedi et al., 2012). Liao et al., applied consecutive step consist of

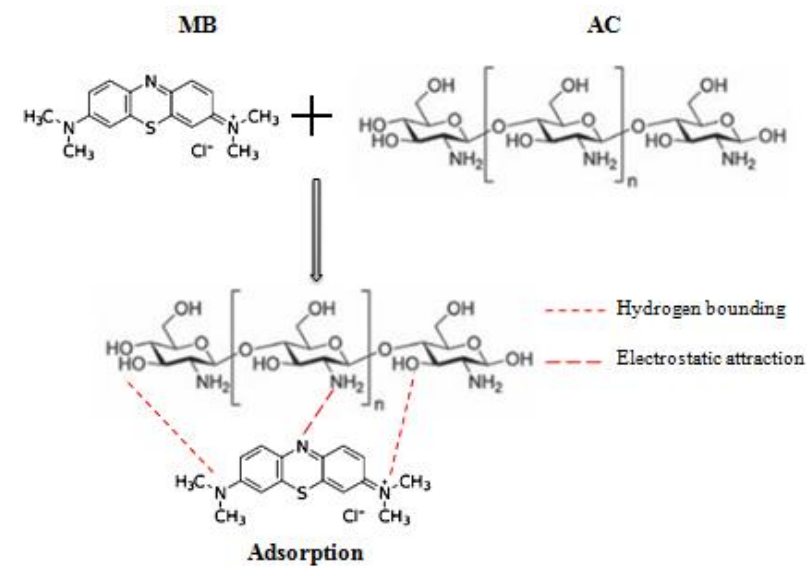

Figure 7. Mechanisms of MB de adsorption onto AC-NM

Also, the MB adsorption occurs possibly through surface exchanges until the functional sites are completely unavailable; subsequently, dye molecules diffuse into PAC for more interactions possibly hydrogen bonding and hydrophobic interactions. This subject developed by else investigator that indicates intraparticle diffusion can be rate controlling step(Hizal et al., 2015). As noted in Table 4, $k$ constant in second-order was obtained 0.02 . Thus, raise of this value indicated that increased in $\mathrm{MB}$ absorption due to a greater driving force.

\section{Conclusions}

In this study, RSM is demonstrated to be effective and reliable to develop a matematical model ans statical analysis of experimental data. The results of experimentals at the differents values of $\mathrm{pH}$, contact time, adsorbent dosage and dye concentration showed that, the adsorption conditions have significant effects on the removal of $M B$. The quaderatic mathematical model was developed and intraparticle diffusion, external diffusion, and adsorption for MB absorption process that these steps under control kinetics models (Liao et al., 2015). Indeed, in first step external diffusion and adsorption is dominant mechanism but with increasing in time, intraparticle diffusion will be predominance (Fig. 7).

the isoterms studies indicate that the Fre-undlich isotherm was best fit with experimental data. Different kinetic models were also examined, and the results indicate that the adsorption kinetics follow the pseudo-second-order rate. This study conformed that the $N$. microphyllum has comparatively high adsorption capacity and can be used as cost effectiveness natural absorbant.

\section{References}

Albadarin A.B. and Mangwandi C. (2015), Mechanisms of Alizarin Red $S$ and Methylene blue biosorption onto olive stone byproduct: Isotherm study in single and binary systems, Journal of Environmental Management, 164, 86-93.

Almasi A., Navazeshkha F. and Mousavi S.A. (2017), Biosorption of lead from aqueous solution onto Nasturtium officinale: performance and modeling Biosorption of lead from aqueous solution onto Nasturtium officinale: performance and modeling, Desalination and Water Treatment, 65, 443-450.

Almeida C.A.P., Debacher N.A., Downs A.J., Cottet L. and Mello C.A.D. (2009), Removal of methylene blue from colored effluents by adsorption on montmorillonite clay, Journal of Colloid and Interface Science, 332, 46-53.

Bezerra M.A., Santelli R.E., Oliveira E.P., Villar L.S. and Escaleira L.A. (2008), Response surface methodology (RSM) as a tool for optimization in analytical chemistry, Talanta, 76, 965-977.

Bouaziz F., Koubaa M., Kallel F., Chaari F., Driss D., Ghorbel R.E. and Chaabouni S.E. (2015), Efficiency of almond gum as a lowcost adsorbent for methylene blue dye removal from aqueous solutions, Industrial Crops and Products, 74, 903-911.

Carrott P.J.M., Nabais J.M.V., Carrott Ribeiro M.M.L. and Pajares J.A. (2001), Preparation of activated carbon fibres from acrylic textile fibres, Carbon, 39, 1543-1555.

Cui J., Ma X., Wu X. and Zhang X. (2016), Adsorption of 2, 4, 6trichlorophenol by magnetic mesoporous $\mathrm{SiO}_{2}$ and the adsorption capacity regeneration by UV photolysis, Desalination and Water Treatment, 57, 6614-6623. 
Demim S., Drouiche N., Aouabed A., Benayad T., Couderchet M. and Semsari S. (2014), Study of heavy metal removal from heavy metal mixture using the ccd method, Journal of Industrial and Engineering Chemistry, 20, 512- 520.

Dotto G.L., Santos J.M., Rodrigues I.L., Rosa R., Pavan F.A. and Lima EC. (2015), Adsorption of Methylene Blue by ultrasonic surface modified chitin, Journal of Colloid and Interface Science, 446, 133-140.

Drage T.C., Arenillas A., Smith K.M., Pevida C., Piippo S. and Snape C.E. (2007), Preparation of carbon dioxide adsorbents from the chemical activation of urea- formaldehyde and melamine-formaldehyde resins, Fuel, 86, 22-31.

Federation W.E. and A.P.H. (2005), Standard methods for the examination of water and wastewater." American Public Health Association (APHA): Washington, DC, USA.

Fernandes A.N., Almeida C.A., Menezes C.T., Debacher N.A. and Sierra M.M. (2007), Removal of methylene blue from aqueous solution by peat, Journal of Hazardous Materials, 144, 412-419.

Ghaedi M., Heidarpour S., Kokhdan SN., Sahraie R., Daneshfar A. and Brazesh B. (2012), Comparison of silver and palladium nanoparticles loaded on activated carbon for efficient removal of Methylene blue: Kinetic and isotherm study of removal process, Powder Technology, 228, 18-25.

Hameed B.H., Ahmad A.A. and Aziz N. (2007), Isotherms, kinetics and thermodynamics of acid dye adsorption on activated palm ash, Chemical Engineering Journal, 133, 195-203.

Hayat H., Mahmood Q., Pervez A., Bhatti Z.A. and Baig S.A. (2015), Comparative decolorization of dyes in textile wastewater using biological and chemical treatment, Separation and Purification Technology, 154, 149-153.

Hizal J., Demirçivi P., Karadirek Ş. and Apak R. (2015), Investigation of individual and competitive adsorption of $\mathrm{Cu}$ (II), $\mathrm{Cd}$ (II), and $\mathrm{Pb}$ (II) on montmorillonite in terms of surface complexation and kinetic properties of $\mathrm{Cu}$ (II) adsorption, Desalination and Water Treatment, 57, 1-13.

Islam M.A., Ahmed M.J., Khanday W.A., Asif M. and Hameed B.H. (2017), Mesoporous activated carbon prepared from $\mathrm{NaOH}$ activation of rattan (Lacosperma secundiflorum) hydrochar for methylene blue removal, Ecotoxicology and Environmental Safety, 138, 279-285.

Jia Y.F., Xiao B. and Thomas K.M. (2002), Adsorption of metal ions on nitrogen surface functional groups in activated carbons, Langmuir, 18, 470-478.

Khashij M., Moheb A., Mehralian M. and Gharloghi M. (2016), Modeling of the adsorption breakthrough behaviors of 4chlorophenol in a fixed bed of nano graphene oxide adsorbent, Journal of Water Supply: Research and Technology-AQUA, 65, 127-134.

Kumar A. and Jena H.M. (2016), Removal of methylene blue and phenol onto prepared activated carbon from Fox nutshell by chemical activation in batch and fixed-bed column, Journal of Cleaner Production, 137, 1246-1259.

Li Y., Du Q., Liu T., Peng X., Wang J., Sun J., Wang Y., Wu S., Wang Z., Xia Y. and Xia L. (2013), Comparative study of methylene blue dye adsorption onto activated carbon, graphene oxide, and carbon nanotubes, Chemical Engineering Research and Design, 91, 361-368.

Liao I.H., Huang J.H., Wang S.L., Cheng M.P. and Liu J.C. (2015), Adsorptions of $\mathrm{Cd}$ (II) and $\mathrm{Pb}$ (II) in aqueous solution by ricestraw char, Desalination and Water Treatment, 57, 1-8.
Liu Y., Wang J., Zheng Y. and Wang A. (2012), Adsorption of methylene blue by kapok fiber treated by sodium chlorite optimized with response surface methodology, Chemical Engineering Journal, 184, 248-255.

Low L.W., Teng T.T., Alkarkhi A.F., Ahmad A. and Morad N. (2011), Optimization of the adsorption conditions for the decolorization and COD reduction of methylene blue aqueous solution using low-cost adsorbent, Water, Air, \& Soil Pollution, 214, 185-195.

Marrakchi F., Ahmed M.J., Khanday WA., Asif M. and Hameed B.H. (2017), Mesoporous-activated carbon prepared from chitosan flakes via single-step sodium hydroxide activation for the adsorption of methylene blue, International journal of biological macromolecules, 98, 233- 239.

Martins A. and Nunes N. (2015), Adsorption of a Textile Dye on Commercial Activated Carbon: A Simple Experiment To Explore the Role of Surface Chemistry and Ionic Strength, Journal of Chemical Education, 92, 143-147.

Mitrogiannis D., Markou G., Çelekli A. and Bozkurt H. (2015), Biosorption of methylene blue onto Arthrospira platensis biomass: Kinetic, equilibrium and thermodynamic studies, Journal of Environmental Chemical Engineering, 3, 670-680.

Mousavi S.A., Almasi A., Kamari Z., Abdali F. and Yosefi Z. (2014), Application of the central composite design and response surface methodology for the treatment of Kermanshah landfill leachate by a sequencing batch reactor, Desalination and Water Treatment, 56, 622-628.

Mousavi S.A. and Ibrahim S. (2014), Application of response surface methodology (RSM) for analyzing and modeling of nitrification process using sequencing batch reactors, Desalination and Water Treatment, 5, 1-10.

Mousavi S.A., Ibrahim S. and Aroua M.K. (2012), Sequential nitrification and denitrification in a novel palm shell granular activated carbon twin-chamber upflow bio-electrochemical reactor for treating ammonium-rich wastewater, Bioresource Technology, 125, 256-266.

Özer A. and Dursun G. (2007), Removal of methylene blue from aqueous solution by dehydrated wheat bran carbon, Journal of Hazardous Materials, 146, 262-269.

Plaza M.G., Pevida C., Arias B., Fermoso J., Casal M.D., Martín C.F., Rubiera F. and Pis J.J. (2009), Development of low-cost biomass-based adsorbents for postcombustion $\mathrm{CO}_{2}$ capture, Fuel, 88, 2442-2447.

Plaza M.G., Pevida C., Arias B., Fermoso J., Rubiera F. and Pis J.J. (2009), A comparison of two methods for producing $\mathrm{CO}_{2}$ capture adsorbents, Energy Procedia, 1, 1107-1113.

Rodríguez A., García J., Ovejero G. and Mestanza M. (2009), Adsorption of anionic and cationic dyes on activated carbon from aqueous solutions: equilibrium and kinetics, Journal of Hazardous Materials, 172, 1311-1320.

Rohilla S.K., Salar R.K. and Kumar J. (2012), Optimization of physiochemical parameters for decolorization of Reactive Black HFGR using soil fungus, Aspergillus allhabadii MTCC 9988, Journal of Bioremediation and Biodegradation, 3, 2.

Siriwardane R.V., Shen M.S., Fisher E.P. and Losch J. (2005), Adsorption of $\mathrm{CO}_{2}$ on zeolites at moderate temperatures, Energy and Fuels, 19, 1153-1159.

Srinivasan A. and Viraraghavan T. (2010), Oil removal from water by fungal biomass: A factorial design analysis, Journal of Hazardous Materials, 175, 695-702. 
Strauss L.C. (2007), Appendix v: Global-Effluent-Guidelines. v 1.2 http://www2.epa.gov/eg/industrial-effluent-guidelines. 141174.

Tan I.A., Ahmad A.L. and Hameed B.H. (2008), Adsorption of basic dye on high surface-area activated carbon prepared from coconut husk: Equilibrium, kinetic and thermodynamic studies, Journal of Hazardous Materials, 154, 337-346.

Tan K.B., Vakili M., Horri B.A., Poh P.E., Abdullah A.Z. and Salamatinia B. (2015), Adsorption of dyes by nanomaterials: Recent developments and adsorption mechanisms, Separation and Purification Technology, 150, 229 -242.

Turan Beyli P., Doğan M., Alkan M., Türkyılmaz A., Turhan Y., Demirbaş Ö. and Namli H. (2015), Characterization, adsorption, and electrokinetic properties of modified sepiolite, Desalination and Water Treatment, 57, 1 -14.

Veličković Z., Ivanković N., Striković V., Karkalić R., Jovanović D., Bajić Z. and Bogdanov J. (2016), Adsorption of arsenazo (III) by phosphorus -containing polymer sorbent, Journal of the Serbian Chemical Society, 2016, 45.

Vickers P.E., Watts J.F., Perruchot C. and Chehimi M.M. (2000), The surface chemistry and acid -base properties of a PAN based carbon fibre, Carbon, 38, 675 -689.

Wu J., Zhang H., Oturan N., Wang Y., Chen L. and Oturan M.A. (2012), Application of response surface methodology to the removal of the antibiotic tetracycline by electrochemical process using carbon -felt cathode and DSA $\left(\mathrm{Ti}^{2} / \mathrm{RuO}_{2}-\mathrm{IrO}_{2}\right)$ anode, Chemosphere, 87, 614 -620.

Yuan W., Yuan P., Liu D., Yu W., Laipan M., Deng L. and Chen F. (2016), In situ hydrothermal synthesis of a novel hierarchically porous TS $-1 /$ modified -diatomite composite for methylene blue $(\mathrm{MB})$ removal by the synergistic effect of adsorption and photocatalysis, Journal of Colloid and Interface science, 462, $191-199$.

Zhang Z., Zhang Z., Fernández Y., Menéndez J.A., Niu H., Peng J., Zhang L. and Guo S. (2010), Adsorption isotherms and kinetics of methylene blue on a low -cost adsorbent recovered from a spent catalyst of vinyl acetate synthesis, Applied Surface Science, 256, 2569 -2576. 